\title{
The organism - reality or fiction?
}

\section{CHARLES T WOLFE SCOUTS THE ANSWERS}

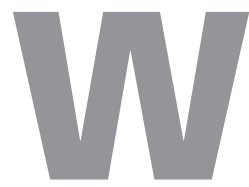

hat is an "organism"? A state of matter, or a particular type of living being chosen as an experimental object, like the

fruit fly or the roundworm c. elegans, which are "model organisms"? Organisms are real, in a trivial sense, since flies and Tasmanian tigers and Portuguese men-o-war are (or were, in the case of the Tasmanian tiger) as real as tables and chairs and planets. But at the same time, they are meaningful constructs, as when we describe Hegel or Whitehead as philosophers of organism in the sense that they insist on the irreducible properties of wholes - sometimes, living wholes in particular. In addition, the idea of organism is sometimes appealed to in a polemical way, as when biologists or philosophers angrily oppose a more "holistic" sense of organism to a seemingly cold-hearted, analytic and dissective attitude associated with "mechanism" and "reductionism".
We murder to dissect, or as the famous physicist Niels Bohr warned, we may kill the organism with our too-detailed measurements.

Historically, the word "organism" emerged in the late seventeenth and early eighteenth centuries, in particular, in the debate between the philosopher and polymath Gottfried Wilhelm Leibniz and the chemist and physician GeorgErnest Stahl, the author of a 1708 essay On the difference between mechanism and organism. Both Leibniz and Stahl agree that organisms are not the same as mere mechanisms, but they differ on how to account for this difference. For Leibniz, it is more of a difference in complexity (for him, organisms are machines which are machines down to their smallest parts), whereas for Stahl, the organism is a type of whole governed by the soul (at all levels of our bodily functioning, from the way I blink if an object comes too close to my eyes, to "my" fighting off 


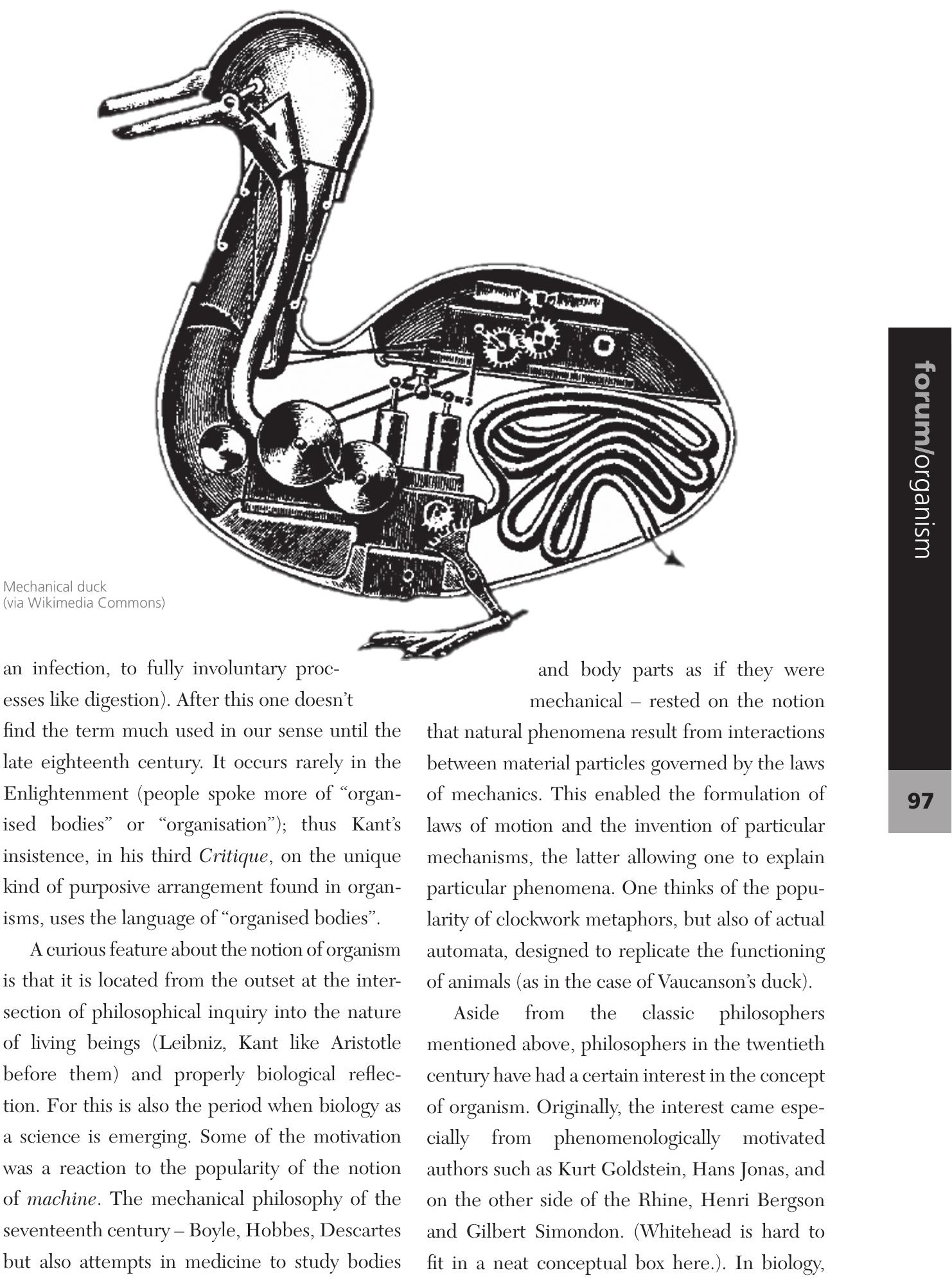




\section{With the rise of genetics the organism was consigned to the dustbin of history}

for a long time with the rise of genetics and popular concepts such as the "selfish gene", the organism was viewed as consigned to the dustbin of history. Any privileged status granted to irreducible wholes will disappear - on this view - in favour of the molecularisation of biological entities. Thus the journal American Zoologist asked in 1989, "Do organisms exist?", and described the organism as the "Phoenix" of biology. As the distinguished philosopher of biology David Hull put it, "both scientists and philosophers take ontological reduction for granted .... Organisms are 'nothing but' atoms, and that is that." Yet the story does not end there. Biologists interested in evolution, but also developmental processes, ecosystems, and problem cases such as coral reefs or symbiotic organisms, have begun to ask questions again concerning the nature of biological identity and individuality, which as a side effect brings back in a role for philosophy. Perhaps it is a false or empty promise to insist that the world is made up of atoms or genes and replicators, and nothing else; perhaps we should speak, with the biologists Queller and Strassman, of "degrees of organismality".

The degree of reality of the concept of organism, then, is bound up with a variety of other issues. One is the status of biology and biological entities with regard to physics: how do we decide what gets to be "the most real" sorts of entities? Another is the role for philosophy. For there is a kind of symbiotic - or is it parasitical? relationship between the metaphysician looking to examples from the biological world to support her claims about identity, and the biologist appealing to metaphysical notions to differentiate the "systems" she studies from atoms, or machines, or numbers. Thirdly, the more ideological implications of the organism concept tie it directly to what sort of position we take on the relation between humanity and scientific explanations.

Let's distinguish between strong and weak conceptions of organism, where the weak conception simply holds that organisms are types of organisation with some specific features, like homeostasis, which are not found in storms or supernovas, whereas the strong conception insists on a real, irreducible uniqueness of organisms and challenges our entire scientific world-picture on the basis thereof. Thus the defender of the "strong concept" of organism, not content to assert like Heidegger that "science does not think" and end it there, will try and shift the conflict into the territory of science, and will say that there should be a science of the organism itself, a holistic science, a "new paradigm", which would overcome or refute the excessively reductionist paradigm we have been saddled with since the Scientific Revolution.

The problem with all of this, whether or not one accepts the verdict of "mainstream science" that the organism in itself either does not exist or does not matter, is that this kind of defence or challenge has something very normative about it. It is in the name of a certain idea of value that 
one defends a particularity of living beings; think of the expression "pro-life"! To those who insist that there is something about life, the fact of life, and the unique features of living beings which almost prior to argument is a value, I would reply with Nietzsche's comment that "Life is not an argument. Among the conditions of life might be error," a comment which harks back to old Epicurean themes (the world is composed of atoms and chance) but which can also be heard in Darwinian terms: the fact that one species rather than other survived has a dimension of "accident" to it.

I suggest that a useful concept of organism, if we are to have one - a concept of organism worth wanting, in Daniel Dennett's phrase - will have to be compatible with a broad commitment to philosophical naturalism. That is, it will not seek to oppose organisms to the rest of physical nature, neither in terms of their possessing a mysterious inner life which other beings do not possess, nor because they possess a mysterious "vital force".

\section{The word "organism" emerged in a debate between Leibniz and the chemist Georg- Ernest Stahl}

In some sense, as the great eighteenth-century French naturalist Buffon wrote, "the organic is the most ordinary product of nature." Of course, if we push that notion of ordinariness too far, we lose sight of an interesting feature of organisms, including ourselves: that they live in their own environments. Lizards, finches, tarantulas, primates and humans all live in, interact with, and customise their environments which we can describe as meaningful (think e.g. of the bower bird): they are worlds.

Rather than arguing over what is most real atoms and protons, or hearts and lungs - it could

\section{How do we decide what gets to be "the most real"?}

be interesting to take account of the way in which organisms relate to the meaningful traits of their environment (this is partly discussed by biologists as "niche construction"), since it is also our own doing.

Rather than asserting that "organisms are special because of their special relation between whole and parts" (as in Aristotle's arresting image that a hand severed from the body is no longer a hand), or more empirically, "organisms are special because they digest, sweat, fear, love, have high blood pressure or low blood sugar" (a claim partly weakened by artificial constructions from Vaucanson's duck to Wim Delvoye's "Cloaca"), we would be better off acknowledging that there is always an imaginative, and even a fictional component in our attempts to make sense of organisms. Even the most die-hard mechanists make use of analogies and models to understand that most complex of machines, the living body. A mechanical model is nothing else than a heuristic model designed to explain something about the object which "strong organicists" seek a monopoly on, Life.

When Kant (in)famously declared that there will never be a Newton of even a mere blade of grass - that is, that science, which he understood 
mathematically specifiable mechanistic science, could never account for or "discover" the laws governing organic beings - or when Leibniz insisted that the difference between a "machine of nature" (his term for an organism) and an artificial machine is that a machine of nature, a living being, is a machine to infinity, they are both clinging to the idea of a certain special "something", whether that be "wonder tissue" or "selfhood", which constructions and reconstructions cannot grasp.

In contrast, we should recall that an important dimension of mechanical models is their heuristic dimension: mechanisms are also "built so as to see what is inside them". If organisms are particular, complex cases of mechanisms, this does not amount to the rather knee-jerk reductionist insistence that "Life" does not exist, or that there are only atoms or genes.

Let me put this point differently, and draw out some of its implications. First, organisms are not free from our acts of imaginative construction. Second, there is no absolute separation between organisms and mechanisms, or organisms and the physical world as a whole. Third, if our desire to preserve the uniqueness of flesh-and-blood, living, breathing, suffering and/or joyous entities over and against an imagined cold, dead, inert Necropolis takes the form of a list of irreducible empirical features, we are not on the right track. For one thing, we do not have any absolute, empirical or conceptual criterion with which we could distinguish a living being from a non-living being, whether the integrity of the organism, its self-regulation (homeostasis), or "metabolism". These features are always post facto observations, starting from within a temporal process. In that sense, the relation between living and non-living,

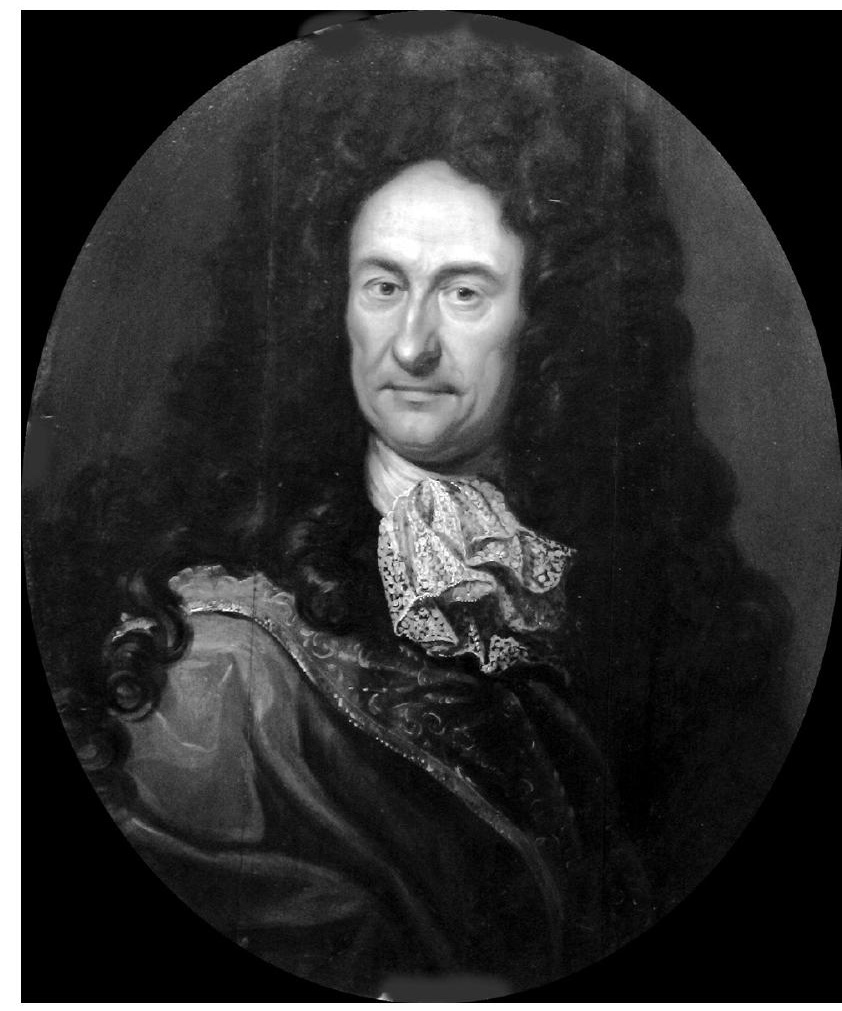

Gottfried Wilhelm Leibniz, oils on wood by Johann Friedrich Wentzel c1700 (via Wikimedia Commons)

organism and machine, is an empirical relation, which does not allow one to posit qualitative differences between laws of nature. As the theoretical biologist Robert Rosen says, "there is as yet no list of tests, characteristics or criteria we can apply to a given material system that can decide whether that system is an organism or not"; "the decision as to whether a given system is an organism is entirely a subjective, intuitive one, based on criteria that have so far resisted formalization."

Any strong claims about the reality of organisms will be based on (a) heuristic fiction(s)! The 
latter phrase is meant to convey, also, that organisms are a cognitive construct of our minds: in order to be able to understand an entity we need to project certain features onto it; but these features should not be held to be constitutive of certain "regions" of the real. Those of us who are fond of Darwinian flourishes would add that it may be a survival trait to be able to "read" certain organisms as organisms rather than as bundles of molecules. Thus, in an evocative example suggested by Dennett, if I am being pursued by a tiger in a jungle, it is a better idea for me to view that tiger as an organism - as a total, interconnected system of parts with unified functions and goals, including "eating me" - rather than as a set of atoms or molecules which I try to calculate the laws of: if I view it in the latter way, the chances of my making it out alive are much reduced. Thus, seeing the world, or at least parts of the world, from an organismic standpoint would be a competitive advantage.

The category of "organism" has returned, if not to centre stage then at least to the horizon of the active interests of biologists - whether they are concerned with evolution, ecosystems, systems biology, physiology, developmental processes and the like - and philosophers concerned either with what the life sciences tell us about some of our fundamental preoccupations, and/ or with classic metaphysical problems like individuality and personal identity. In what sense am I "one" with the bacteria in my gut? In what sense is a coral reef one organism, or colony individuals like the Portuguese man-o-war, or symbiotic cases like the squid which ingests phosphorescent bacteria so that it can hunt at night, rendered invisible by the luminescence on its back?
The other question I have discussed, concerning, not the individuality of organisms but their reality - what is different, or special about them as compared to machines, or physical Nature as a whole, including as it pertains to the old "what is Life?" question (where the difference is more, "a living body versus a corpse") - has faded away, in comparison with that of individuality. But if such a question were asked, we

\section{Organisms are not free from our acts of imaginative construction}

might say that the organism is nothing other than the production of a vital artificiality or fiction; and it is never alone: an organism can only be a "paradigmatic individual" in and through its relation to a population, a group or an environment as a whole. If there is nothing unique about organisms over and against the rest of Nature; if, as Buffon thought, "the organic is the most ordinary product of nature," what does exist is a certain approach to reality, a fiction, the way a particular bundle of living matter exists, feels joy and regret, remembers, ages and thereby briefly saturates a particular intersection in the great causal nexus of the world.

Charles T Wolfe is a research fellow in philosophy
at Ghent University, in Belgium 